This item was submitted to Loughborough's Research Repository by the author.

Items in Figshare are protected by copyright, with all rights reserved, unless otherwise indicated.

\title{
Default effects, transaction costs, and imperfect information
}

PLEASE CITE THE PUBLISHED VERSION

http://dx.doi.org/10.1016/j.econlet.2013.02.022

\section{PUBLISHER}

(C) Elsevier

LICENCE

CC BY-NC-ND 4.0

\section{REPOSITORY RECORD}

Wilson, Chris M., Luke Garrod, and Alistair Munro. 2019. "Default Effects, Transaction Costs, and Imperfect Information". figshare. https://hdl.handle.net/2134/15288. 
This item was submitted to Loughborough's Institutional Repository (https://dspace.lboro.ac.uk/) by the author and is made available under the following Creative Commons Licence conditions.

\section{creative
commons}

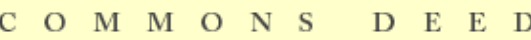

Attribution-NonCommercial-NoDerivs 2.5

You are free:

- to copy, distribute, display, and perform the work

Under the following conditions:

Attribution. You must attribute the work in the manner specified b the author or licensor.

Noncommercial. You may not use this work for commercial purposes.

No Derivative Works. You may not alter, transform, or build upon this work.

- For any reuse or distribution, you must make clear to others the license terms of this work.

- Any of these conditions can be waived if you get permission from the copyright holder.

Your fair use and other rights are in no way affected by the above.

This is a human-readable summary of the Leqal Code (the full license).

\section{Disclaimer 만}

For the full text of this licence, please go to: http://creativecommons.org/licenses/by-nc-nd/2.5/ 


\title{
Default Effects, Transaction Costs, and Imperfect Information
}

By

\author{
Chris M. Wilson \\ Luke Garrod \\ Alistair Munro
}

December 2012

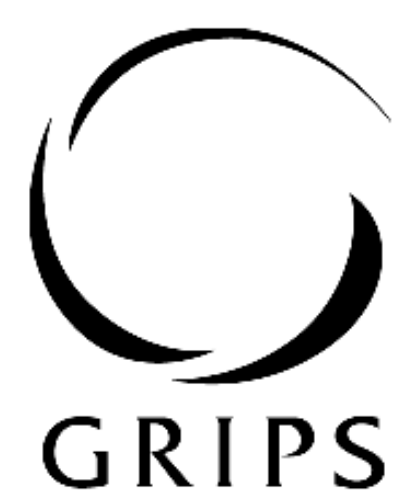

National Graduate institute FOR POLICY STUDIES

National Graduate Institute for Policy Studies

7-22-1 Roppongi, Minato-ku,

Tokyo, Japan 106-8677 
Default Effects, Transaction Costs, and Imperfect Information

\author{
Chris M. Wilson ${ }^{a}$, Luke Garrod ${ }^{a}$ and Alistair Munro ${ }^{b}$
}

December 2012

\begin{abstract}
We develop a decision framework with imperfect information to analyze the effects of transaction costs on the tendency for individuals to remain with a default option. We demonstrate how transaction costs can be a more important source of such default effects than commonly thought. A further, potentially surprising result shows that transaction costs are able to explain why some forms of default effects increase with the number of options.
\end{abstract}

Keywords: Default effect; transaction cost; imperfect information.

JEL Codes: D03, D83

${ }^{a}$ School of Business and Economics, Loughborough University, LE11 3TU, UK. Corresponding author: c.m.wilson@lboro.ac.uk, +44(0)1509222733.

${ }^{b}$ National Graduate Institute for Policy Studies, Roppongi 7-22-1, Minato-ku, Tokyo, 106-8677, Japan. 


\section{Introduction}

Individuals often exhibit a disproportionate tendency to remain with a default option, even when there are potentially better alternatives. Evidence for this important policy issue comes from many contexts, including contract choice, car options, organ donation, and especially retirement plans, where savings choices are strongly aligned to the default participation status and contribution rate (see the review by DellaVigna 2009).

One explanation of such default effects concerns decision inertia. ${ }^{1}$ This can result from transaction costs and be further enhanced by procrastination via behavioral self-control problems (see Madrian and Shea 2001). The current literature focuses on the behavioral mechanism (e.g. Choi et al 2003, Carroll et al 2009) because direct transaction costs (switching costs) appear insufficient, due to the relatively low effort often required to administer a change from the default (e.g. DellaVigna 2009, p.323). However, while procrastination is undoubtedly important, both this reasoning and the resulting models overlook the indirect transaction costs (information costs) of identifying and learning about alternatives. This omission may be significant because such costs can be considerable, especially when the alternatives are complex, as in the case of retirement plans.

In contrast, this paper explicitly analyzes the role of both direct and indirect transaction costs by developing a search-theoretic model of individual choice with imperfect information about the benefits of each alternative. ${ }^{2}$ It builds on Wilson (2012) who characterizes optimal consumer behavior under both forms of transaction costs and examines their impact on oligopoly competition. By extending his analysis within our different setting, we re-examine the importance of transaction costs in two ways. First, we consider how the inclusion of indirect transaction costs affects the ability of transaction costs to explain the existence of default effects. Second, we explore the extent to which transaction costs can account for the empirical evidence which suggests that default effects increase with the number of options (e.g. Samuelson and Zeckhauser 1988).

\footnotetext{
${ }^{1}$ Other explanations, such as those within the reference dependent preferences literature (Munro and Sugden, 2003; DellaVigna, 2009) are often framed in terms of a related concept, the status quo bias (Samuelson and Zeckhauser 1988). Although our model focuses on default effects, it also applies to the status quo bias.

${ }^{2}$ Search-theoretic models have been used to explore related phenomena such as choice overload (e.g. Kuksov and Villas-Boas 2010) but not default effects.
} 


\section{Model}

An individual must select either a default option, $d$, or one of $(n-1)$ alternatives, where $n$ is an integer greater than one. The benefit of any option $j=\{d, 1, \ldots, n-1\}$ derives from a 'match value', $\varepsilon_{j}$, which is drawn independently from a uniform distribution on $[0,1]$. This avoids any systematic preference-based sources of default effects. As consistent with the case where the default is common or where information about the default is readily available, we assume that the individual is sufficiently familiar with the default that she knows its match value, $\varepsilon_{d}$. However, to introduce imperfect information, we allow the individual to be initially uninformed about the alternatives.

If the individual takes no action, she automatically receives the default. If she wishes to select some alternative, $j \neq d$, she must first incur an information cost, $c>0$, to identify the alternative and learn its match value, $\varepsilon_{j}$. The individual can investigate any number of alternatives sequentially, incurring $c$ each time. After each investigation, she can choose to either remain with the default at no extra cost or switch to an identified alternative for an additional switching cost, $s>0 .^{3}$

The model is deliberately simple, but our main results can hold under more general assumptions. For instance, if it was unnecessary to incur $c$ to identify an alternative so that the individual could change to an alternative without knowing its match value, then it would still be optimal to make a prior investigation provided $c$ was sufficiently small. ${ }^{4}$

\section{Analysis}

Let $\widehat{x}$ be the value of $x$ that solves $c=\int_{x}^{1}(\varepsilon-x) d \varepsilon$, such that

$$
\widehat{x}=1-\sqrt{2 c}
$$

Lemma 1. The individual's optimal decision rule is then:

Step 1: Accept the default immediately if $\varepsilon_{d} \geq \widehat{x}-s$. Otherwise move to Step 2.

Step 2: Investigate alternatives until the discovery of some $\varepsilon_{j} \geq \widehat{x}$ for $j \neq d$, or until no alternative remains.

\footnotetext{
${ }^{3}$ Alternatively, $s$ can be interpreted as a recommendation effect, whereby the individual falsely believes that the default is endorsed in some way.

${ }^{4}$ Using later notation, this requires $\widehat{x} \geq 0.5(c \leq 1 / 8)$ so that the benefits of investigating, which can be considered equal to $\widehat{x}-s$, are larger than those from making an uninformed change, $E(\varepsilon)-s$.
} 
Step 3: Select the best option from the default and the set of identified alternatives, I, which offers $\max \left\{\varepsilon_{d}, \varepsilon_{j}-s\right\} \forall j \in I$.

This follows straightforwardly from Lemma 1 of Wilson (2012). In Step 1, the individual decides whether to start investigating the alternatives. Using standard induction arguments, this reduces to a seemingly-myopic comparison between the benefits of accepting the default immediately, $\varepsilon_{d}$, and the expected net gains from investigating one alternative. To calculate the latter, note that the individual would only prefer the alternative to the default if its match value, $\varepsilon$, was greater than $\varepsilon_{d}+s$. Thus, the expected net gains are

$$
-c+\int_{0}^{\varepsilon_{d}+s} \varepsilon_{d} d \varepsilon+\int_{\varepsilon_{d}+s}^{1}(\varepsilon-s) d \varepsilon
$$

Equating this to $\varepsilon_{d}$ and letting $\varepsilon_{d}+s \equiv x$ implies that the individual is indifferent when $c=\int_{x}^{1}(\varepsilon-x) d \varepsilon$. This provides the implicit definition for $\widehat{x}$ used in (1). Consequently, she will not investigate if $x \geq \widehat{x}$ or equivalently, $\varepsilon_{d} \geq \widehat{x}-s$. Since $c>0$ ensures $\widehat{x}<1$, we know $\widehat{x}-s<1$, given $s>0$.

In Step 2, the individual decides whether to continue investigating alternatives after having made one (or more) previous investigation(s). Using similar logic, this reduces to a comparison between the benefits from stopping immediately and the expected net benefits from investigating one further alternative. It follows that the individual will optimally stop only on the discovery of an alternative with a sufficiently large match value, $\varepsilon \geq \widehat{x}$. By construction, the benefits from this alternative, $\varepsilon-s$, will necessarily exceed the benefits of the default, $\varepsilon_{d}$. In Step 3, the individual then selects her best available option.

\section{Measures of Default Effects}

One common measure of default effects is the probability that the default is selected, $\operatorname{Pr}(d)$. Here,

$$
\operatorname{Pr}(d)=\int_{\max \{\widehat{x}-s, 0\}}^{1} d \varepsilon+\int_{0}^{\max \{0, \widehat{x}-s\}}(\varepsilon+s)^{n-1} d \varepsilon .
$$

The first term is the probability that the individual accepts the default immediately without any investigations, $\operatorname{Pr}\left(\varepsilon_{d} \geq \widehat{x}-s\right)$. The second term is the probability that the individual selects the default after having made at least one investigation. From Lemma 1, 
this only occurs if she investigates all $(n-1)$ alternatives yet still prefers the default. This requires i) $\varepsilon_{d}<\widehat{x}-s$ from Step 1, ii) $\varepsilon_{j}<\widehat{x} \forall j \neq d$ from Step 2 and iii) $\varepsilon_{d} \geq \varepsilon_{j}-s \forall j \neq d$ from Step 3. As i) and iii) are sufficient to ensure that ii) is satisfied, Step 2 plays no direct role in determining $\operatorname{Pr}(d)$. Finally, if $\widehat{x}-s \leq 0$, then the individual never investigates, so $\operatorname{Pr}(d)=1$.

After simplifying (3),

$$
\operatorname{Pr}(d)= \begin{cases}1-(\widehat{x}-s)+\left(\frac{\widehat{x}^{n}-s^{n}}{n}\right) \in\left(\frac{1}{n}, 1\right) & \text { if } \widehat{x}-s>0 \\ 1 & \text { if } \widehat{x}-s \leq 0 .\end{cases}
$$

However, as a measure, $\operatorname{Pr}(d)$ does not incorporate the fact that the default could be optimal even if $c$ and $s$ were zero, because it could offer the highest match value, $\varepsilon_{d}>\varepsilon_{j}$ $\forall j \neq d$. This occurs with probability,

$$
\operatorname{Pr}(d \mid c=s=0)=\int_{0}^{1} \varepsilon^{n-1} d \varepsilon=(1 / n)>0 .
$$

Consequently, by building on the seminal paper by Samuelson and Zeckhauser (1988), who account for this issue empirically by comparing the number of subjects who selected an exogenous default with the number who selected the same option when it was not framed as a default, we consider two other measures. The 'absolute default effect', $D_{A}$, is the difference in probability between selecting the default and the default offering the highest match value; and the 'relative default effect', $D_{R}$, is this difference as a proportion.

$$
D_{A}=\operatorname{Pr}(d)-\operatorname{Pr}(d \mid c=s=0) \quad \text { and } \quad D_{R}=\frac{\operatorname{Pr}(d)-\operatorname{Pr}(d \mid c=s=0)}{\operatorname{Pr}(d \mid c=s=0)}
$$

From (5) and (6),

$$
D_{A}=\operatorname{Pr}(d)-(1 / n) \quad \text { and } \quad D_{R}=n \operatorname{Pr}(d)-1 .
$$

As an example, suppose $n=10$ such that $\operatorname{Pr}(d \mid c=s=0)=0.1$. If $c=s=0.01$, so that $c$ and $s$ each account for $1 \%$ of the maximum possible gains from selecting an alternative, then $\operatorname{Pr}(d)=0.17, D_{A}=0.07$ and $D_{R}=0.73$. Thus, the default is selected over $70 \%$ more often than it would if $c=s=0$. 


\section{Results}

This section analyzes how the three measures vary first with respect to $c$ and $s$, and then $n$. We assume $\widehat{x}-s>0$ so that $\operatorname{Pr}(d)<1$. When $\operatorname{Pr}(d)=1$, the measures are independent of $c$ and $s$, and our results with regard to $n$ remain qualitatively robust.

\subsection{Transaction Costs}

Proposition 1. $\operatorname{Pr}(d), D_{A}$ and $D_{R}$ are increasing in $c$ and $s$.

Proof: From (7), we need only prove that $\partial \operatorname{Pr}(d) / \partial z>0$ for $z=c, s$. From (4), $\partial \operatorname{Pr}(d) / \partial c \equiv(\partial \operatorname{Pr}(d) / \partial \widehat{x}) \cdot(\partial \widehat{x} / \partial c)=\left(1-\widehat{x}^{n-1}\right) /(1-\widehat{x})$ and $\partial \operatorname{Pr}(d) / \partial s=1-s^{n-1}$. These are positive given $n \geq 2$ and $0<s<\widehat{x}<1$.

An increase in $c$ raises the three measures by lowering the incentives to begin an investigation in Step 1. An increase in $s$ produces a related effect but it also reduces the attractiveness of switching to an identified alternative in Step 3. However, information costs are a relatively more powerful determinant of default effects in the following sense.

Proposition 2. The partial derivatives of $\operatorname{Pr}(d), D_{A}$ and $D_{R}$, with respect to $c$ are larger than the corresponding partial derivatives with respect to $s$.

Proof: From (7), we need only prove that $(\partial \operatorname{Pr}(d) / \partial c)-(\partial \operatorname{Pr}(d) / \partial s)=\left(1-\widehat{x}^{n-1}\right) /(1-$ $\widehat{x})-\left(1-s^{n-1}\right)>0$. This follows given $n \geq 2$ and $0<s<\widehat{x}<1$.

The difference can be substantial; under our example parameters from Section $4, \partial \operatorname{Pr}(d) / \partial c$ is over five times larger than $\partial \operatorname{Pr}(d) / \partial s$. This suggests that the omission of information costs from arguments and models within the existing literature is indeed significant and that transaction costs may be more important than commonly thought. Intuitively, the result is not due to the fact that information costs can be incurred multiple times because it still holds when there is only one alternative. Instead, relative to a unit increase in $s$, a unit increase in $c$ generates a sufficiently greater effect in reducing the expected net gains from making a first investigation. This follows from (2), where the individual expects to incur $c$ with certainty but expects to incur $s$ only if the identified alternative is preferred to the default, which occurs with a probability less than one. 


\subsection{Number of Options}

Proposition 3. $\operatorname{Pr}(d)$ is decreasing in $n$, but $D_{A}$ and $D_{R}$ are increasing in $n$.

Proof: Given $n \geq 2$ and $0<s<\widehat{x}<1$ : i) $\Delta \operatorname{Pr}(d) \equiv \operatorname{Pr}(d \mid n+1)-\operatorname{Pr}(d \mid n)=-\int_{0}^{\widehat{x}-s}(\varepsilon+$ $s)^{n-1}(1-(\varepsilon+s)) d \varepsilon<0$, and ii) $\Delta D_{A} \equiv D_{A}(n+1)-D_{A}(n)=\frac{1-n\left[\widehat{x}^{n}(1-\widehat{x})-s^{n}(1-s)\right]-\left(\widehat{x}^{n}-s^{n}\right)}{n(n+1)}$ and $\Delta D_{R} \equiv D_{R}(n+1)-D_{R}(n)=1-(\widehat{x}-s)-\left[x^{n}(1-\widehat{x})-s^{n}(1-s)\right]$ are both positive because they are decreasing in $\widehat{x}$, yet still positive as $\widehat{x} \rightarrow 1$.

Samuelson and Zeckhauser (1988) find empirical evidence that all three measures increase with $n$. Transaction costs cannot easily explain why $\operatorname{Pr}(d)$ rises with $n$. However, perhaps surprisingly, Proposition 3 shows that they are able to explain the evidence for $D_{A}$ and $D_{R}$. Intuitively, an increase in $n$ leaves the decision to start investigating in Step 1 unchanged, yet increases the probability of finding a preferred alternative in Step 2, such that $\operatorname{Pr}(d)$ falls. However, as well as reducing $\operatorname{Pr}(d)$, an increase in $n$ also lowers the probability that the default offers the highest match value, $\operatorname{Pr}(d \mid c=s=0)=(1 / n)$. Given $D_{A}=$ $\operatorname{Pr}(d)-\operatorname{Pr}(d \mid c=s=0)$ and $D_{R}=(\operatorname{Pr}(d) / \operatorname{Pr}(d \mid c=s=0))-1$, the reduction in $\operatorname{Pr}(d \mid c=s=0)$ is always sufficiently large relative to the reduction in $\operatorname{Pr}(d)$ such that both $D_{A}$ and $D_{R}$ increase.

\section{Discussion}

Transaction costs may be a more important source of default effects than commonly thought. However, as transaction costs cannot explain all of the evidence, future research might further consider the interaction between both direct and indirect transaction costs and other explanations. In particular, our search-theoretic framework could offer additional insights when combined with a behavioral model of procrastination, such as Choi et al (2003) or Carroll et al (2009). In contrast to current models that assume full information, this would allow an analysis of the interaction between transaction costs and procrastination under imperfect information, and offer the potential for more general policy advice.

\section{References}

[1] Carroll, G.D., Choi, J.J., Laibson, D., Madrian, B.C., Metrick, A., 2009. Optimal Defaults and Active Decisions. Quarterly Journal of Economics. 124, 1639-1674. 
[2] Choi, J.J., Laibson, D., Madrian, B.C., Metrick, A., 2003. Optimal Defaults. American Economic Review. 93, 180-185.

[3] DellaVigna, S., 2009. Psychology and Economics: Evidence From the Field. Journal of Economic Literature. 47, 315-372.

[4] Kuksov, D., Villas-Boas, J.M., 2010. When More Alternatives Lead to Less Choice. Marketing Science. 29, 507-524.

[5] Madrian, B.C., Shea, D.F. 2001. The Power of Suggestion: Inertia in 401(k) Participation and Savings Behavior. Quarterly Journal of Economics. 116, 1149-1525.

[6] Munro, A., Sugden, R., 2003. On the Theory of Reference-Dependent Preferences. Journal of Economic Behavior and Organization. 50, 407-428.

[7] Samuelson, W., Zeckhauser, R., 1988. Status Quo Bias in Decision Making. Journal of Risk and Uncertainty. 1, 7-59.

[8] Wilson, C.M. 2012. Market Frictions: A Unified Model of Search Costs and Switching Costs. European Economic Review. 56, 1070-1086. 